\title{
Formulation, Development and Optimization of Ciclopirox Emulgel
}

\author{
Swapna Neela ${ }^{*}$, Mayuri Konda ${ }^{2}$, Parijatha Bandigari ${ }^{2}$, Krishna Mohan Chinnala ${ }^{2}$, Balamallesh \\ Kompelly $^{3}$ \\ ${ }^{1,2,3}$ Department of Pharmaceutical Sciences, School of Pharmacy, Nalla Narasimha Reddy Education \\ Society's Group of Institutions, Hyderabad, Telangana, INDIA-500088. \\ *Corresponding Author E-mail: swapnaneela1982@gmail.com
}

\begin{abstract}
The present study was to formulate emulgel using Ciclopirox as drug of choice. Polymers like sodium carboxy methyl cellulose, carbopol 974P and xanthan gum were used as gelling agent in various proportions. Liquid paraffin was used as oil phase and a combination of Span 80 and Tween 80 were used as emulsifying agent. Both oil and aqueous phase were independently warmed to $75^{\circ} \mathrm{C}$. At that point the aqueous phase was added to the oil phase with constant mixing until cooled to room temperature. The gel bases were prepared by scattering diverse concentrations of polymers in refined water. The obtained emulsion was mixed with the gel with gentle stirring to obtain the emulgel. Various formulations were prepared by changing the gelling agent and their concentration. The prepared emulgels were evaluated for physical appearance, $\mathrm{pH}$, spreadability co-efficient, physical stability, drug content and in-vitro drug release. All the formulations were physically stable with the $\mathrm{pH}$ values within the range and have shown good spreadability coefficient. In-vitro diffusion studies were carried out using $\mathrm{pH} 7.4$ phosphate buffer. Formulation F6 was found to be the optimized formulation and it has shown best results with zero order release kinetics and diffusion mechanism.
\end{abstract}

Key words: Ciclopirox, sodium carboxy methyl cellulose, carbopol 974P, xanthan gum.

\section{Introduction}

Topical drug delivery can be defined as the application of a drug containing formulation to the skin to directly treat the cutaneous disorder. The topical drug delivery system is generally used where other routes (such as oral, sublingual, rectal, and parenteral) of drug administration fails or in local skin infection like fungal infection. Topical drug delivery is an attractive route for local and systemic treatment. A unique aspect of dermatological pharmacology is the direct accessibility of the skin as a target organ for diagnosis and treatment. The main advantage of the topical delivery system is to bypass first pass metabolism. Avoidance of the risks and inconveniences of intravenous therapy and the varied conditions of absorption, such as $\mathrm{pH}$ changes, the presence of enzymes, and gastric emptying time are another advantage of the topical drug delivery system [1].

Within the major group of semisolid preparations, the use of transparent gels has expanded both in cosmetics and pharmaceutical preparations. Gels are a relatively newer class of dosage form created by entrapment of large amounts of aqueous or hydroalcoholic liquid in a network of colloidal solid particles, which may consist of inorganic substances, such as aluminum salts or organic polymers of natural or synthetic origin. They have a higher aqueous component that permits greater dissolution of drugs, and 
also permit easy migration of the drug through a vehicle that is essentially a liquid, compared with the ointment or cream base. These are superior in terms of use and patient acceptability.

In spite, so advantageous gels show a major limitation in the delivery of hydrophobic drugs. Hence, to cover up this lacking, emulgel is prepared and used so that even a hydrophobic therapeutic moiety can enjoy the unique properties of gels. In fact, the presence of a gelling agent in the water phase converts a classical emulsion into an emulgel. As the name suggest, they are the combination of gel and emulsion. Both oil-in-water and water-in-oil type of emulsion are used as a vehicle to deliver various drugs to the skin. They also have a high ability to penetrate the skin. Emulgel for dermatological use has several favorable properties such as being thixotropic, greaseless, easily spreadable, easily removable, emollient, non-staining, water-soluble, longer shelf life, bio-friendly, transparent, and appearance [2].

Topical delivery of available ciclopirox formulations as cream, lotion, gel is hindered by the low permeability and so there is need of repeated dosing for a longer period of time for effective treatment. In the present research work an attempt is made for effective delivery of ciclopirox as an emulgel [3].

\section{Materials \& Methods}

\section{Materials:}

Chemicals: Ciclopirox is a gift sample from Sura labs, Hyderabad, India. Sodium CMC, Xanthan gum, Carbapol 974P from Horizon chemicals, Hyderabad, India. Tween 80, span 80, propylene glycol, ethanol, liquid paraffin, methyl Paraben from SD Fine chemicals limited, Hyderabad, India.

Instruments: UV Visible Spectrophotometer from Shimadzu, weighing balance from citizen, $\mathrm{pH}$ meter from Elico, Lab stirrer from Remi.

\section{Method of Preparation:}

\section{A. Preparation of Emulsion}

Preparation of Aqueous Phase:

The aqueous phase of the emulsion was prepared by dissolving Tween 80 in purified water. Methyl Paraben was added to propylene glycol whereas drug was fused in ethanol and the two arrangements were blended with the aqueous phase.

\section{Preparation of Oil Phase:}

The oil phase of the emulsion was prepared by dissolving Span 80 in light liquid paraffin. Both the oil and aqueous phase were independently warmed to $75^{\circ} \mathrm{c}$. At that point the aqueous phase was added to the oil phase with constant mixing until cooled to room temperature.

\section{B.Preparation of Gel}

The gel bases were prepared by scattering diverse concentrations of polymers in refined water independently with steady mixing at a direct speed utilizing lab stirrer. The $\mathrm{pH}$ of all formulations was brought to 6-6.8 utilizing triethanolamine (TEA).

\section{C.Preparation of Emulgel}

The obtained emulsion was mixed with the gel with gentle stirring to obtain the emulgel.

Table 1. Formulation table of Ciclopirox Emulgel

\begin{tabular}{|l|c|c|c|c|c|c|}
\hline Ingredients & F1 & F2 & F3 & F4 & F5 & F6 \\
\hline Ciclopirox(\%) & 0.77 & 0.77 & 0.77 & 0.77 & 0.77 & 0.77 \\
\hline Sodium CMC(\%) & 0.5 & - & - & 1 & - & - \\
\hline
\end{tabular}




\begin{tabular}{|l|c|c|c|c|c|c|}
\hline Xanthan gum(\%) & - & 0.5 & - & - & 1 & - \\
\hline Carbapol 974P(\%) & - & - & 0.5 & - & - & 1 \\
\hline Tween 80(\%) & 0.4 & 0.4 & 0.4 & 0.4 & 0.4 & 0.4 \\
\hline Span 80(\%) & 0.5 & 0.5 & 0.5 & 0.5 & 0.5 & 0.5 \\
\hline Propylene glycol(ml) & 5 & 5 & 5 & 5 & 5 & 5 \\
\hline Methyl Paraben(gm) & 0.01 & 0.01 & 0,01 & 0.01 & 0.01 & 0.01 \\
\hline Liquid paraffin (ml) & 5 & 5 & 5 & 5 & 5 & 5 \\
\hline Ethanol(ml) & 5 & 5 & 5 & 5 & 5 & 5 \\
\hline Water(ml) & Q,S & Q.S. & Q.S. & Q.S. & Q.S. & Q.S. \\
\hline
\end{tabular}

\section{Evaluation Parameters of Emulgels: \\ Visual Appearance and Clarity[4]:}

Visual appearance and Clarity was done under fluorescent light against a white and black back ground for presence of any particulate matter.

pH Measurement[5]:

The $\mathrm{pH}$ of the prepared in-situ gelling system after addition of all the ingredients was measured using $\mathrm{pH}$ meter.

\section{Determination of drug content[6]:}

Accurately weighed quantity of formulation from different batches was measured and transferred to $100 \mathrm{ml}$ volumetric flask. To this $50-70 \mathrm{~mL}$ of $7.4 \mathrm{pH}$ buffer was added and sonicated for $30 \mathrm{~min}$, Volume was adjusted to $100 \mathrm{ml}$. Complete dispersion of contents was ensured visually and the dispersion was filtered using Whattmann Filter Paper. Contents of Ciclopirox was measured at maximum absorbance at $260 \mathrm{~nm}$ using UV-Visible Spectrophotometer(Shimadzu).

\section{Spreadability:}

The spreadability of emulgel[7] formulations was determined 48hrs after preparation, by measuring the spreading diameter of $0.5 \mathrm{~g}$ of emulgel which was placed within a circle of $1 \mathrm{~cm}$ diameter premarked on a glass plate over which a second glass plate $(75 \mathrm{gm})$ was placed. A weight of $425 \mathrm{~g}$ was allowed to rest on the upper glass plate for $5 \mathrm{~min}$ where no more spreading was expected, The increase in the diameter due to spreading of the gels was noted. The spreadability was calculated by using the formula:

$\mathrm{S}=\mathrm{m} . \mathrm{l} / \mathrm{t}$

Where, $\mathrm{S}=$ spreadability,

$\mathrm{m}=$ Weight of the upper plate rested on it $(\mathrm{g})$,

$1=$ diameter of the spreading emulgel $(\mathrm{cm})$

$\mathrm{t}=$ time taken $(\min )$

\section{In-Vitro Release Studies:}

In vitro drug release studies were done by putting the formulation on Millipore film channel $(0.15 \mathrm{~mm})$ between the donor and receptor compartments of an modified Franz diffusion cell. To mimic the corneal epithelial hindrance, the Millipore membrane filter was utilized, as separated cornea won't stay viable beyond $4 \mathrm{hr}$. The receptor compartment of an modified franz diffusion cell was loaded up with $10 \mathrm{~mL}$ freshly prepared $7.4 \mathrm{pH}$ buffer. An aliquot $(1 \mathrm{~mL})$ of test arrangement was set on the Millipore membrane filter, and the opening of the donor cell as fixed with a glass cover slip. The receptor fluid was kept at $37 \pm 0.5^{\circ} \mathrm{C}$ with steady mixing utilizing a Teflon- covered magnetic stirrer bead. 
Samples were with drawn every hour upto $6 \mathrm{hrs}$. Simultaneously buffer was added to the receptor compartment to maintain sink condition. Drug content was estimated by observing the samples at $260 \mathrm{~nm}$ in a spectrophotometer [8].

Kinetic studies:

Different release kinetic equations (zero-order, first-order, Higuchi's equation[9] and Korsmeyerpeppas equation) were applied to interpret the release rate of the drug from matrix systems for the optimized formulation. The best fit with higher correlation (r) was calculated.

In this model, the value of $\mathrm{n}$ characterizes the release mechanism of drug as described in the following table.

Table 2. Drug transport mechanisms suggested based on ' $n$ ' value.

\begin{tabular}{|c|c|c|c|}
\hline S.NO & Release exponent & $\begin{array}{c}\text { Drug transport } \\
\text { mechanism }\end{array}$ & $\begin{array}{c}\text { Rate as a function of } \\
\text { time }\end{array}$ \\
\hline 1 & 0.5 & Fickian diffusion & $\mathrm{t}_{0.5}$ \\
\hline 2 & $0.45<\mathrm{n}=0.89$ & Non fickian transport & $\mathrm{t}_{1}$ \\
\hline 3 & 0.89 & Case II transport & Zero order release \\
\hline 4 & Higher than 0.89 & Super case II transport & $\mathrm{t}_{1}$ \\
\hline
\end{tabular}

To find out the exponent of $\mathrm{n}$ the portion of the release curve, where Mt / M $\infty<0.6$ should only be used. To study the release kinetics, data obtained from in-vitro drug release studies were plotted as $\log$ cumulative percentage drug release versus log time.

\section{Results and Discussion}

In the present study Ciclopirox Emulgel was formulated using polymers like sodium carboxy methyl cellulose, carbopol 974P and xanthan gum as gelling agent in various proportions. Liquid paraffin was used as oil phase and a combination of Span 80 and Tween 80 were used as emulsifying agent. Various formulations were prepared by changing the gelling agent and their concentration. The prepared formulations were later subjected to various evaluation parameters.

\section{Compatibility study of Ciclopirox:}

Compatibility between the drug and polymers was studied by FT-IR method. Pure Ciclopirox and optimized formulation were subjected for FT-IR spectroscopic analysis, to ascertain any interaction between the drug and polymers used. The position of characteristic peaks of pure Ciclopirox was compared with those peaks obtained for optimized formulation. These characteristic bands for Ciclopirox were identifiable and there was no major shift or disappearance in the peak positions. This indicated the drug and excipients are compatible with each other. 


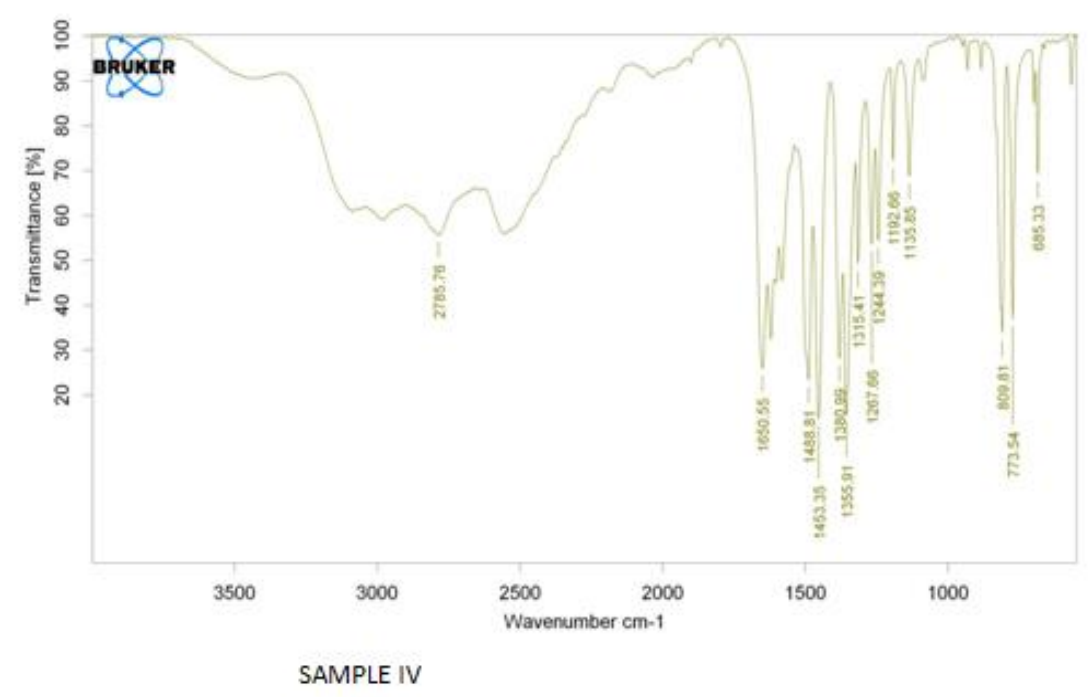

Figure 1. FTIR of drug

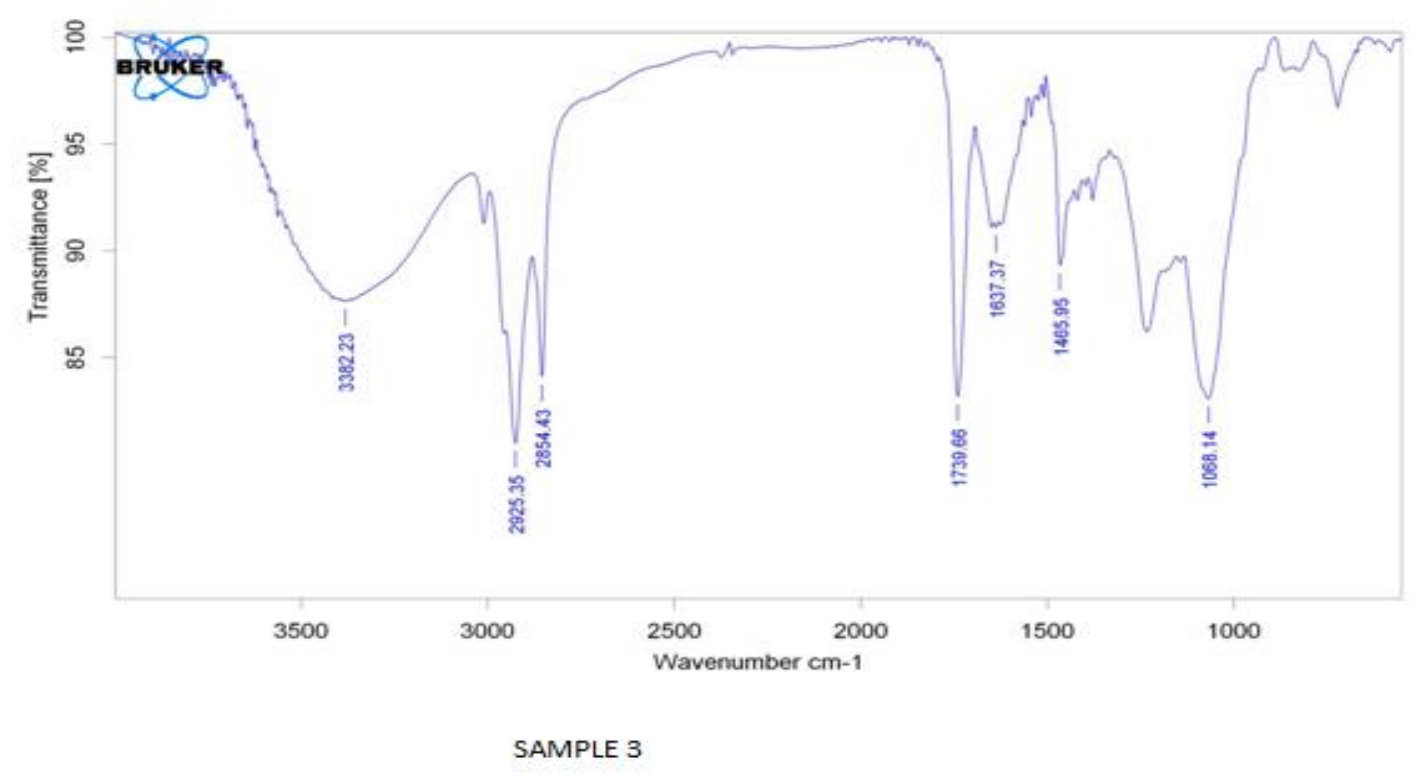

Figure 2. FTIR of Drug + Carbapol 974 


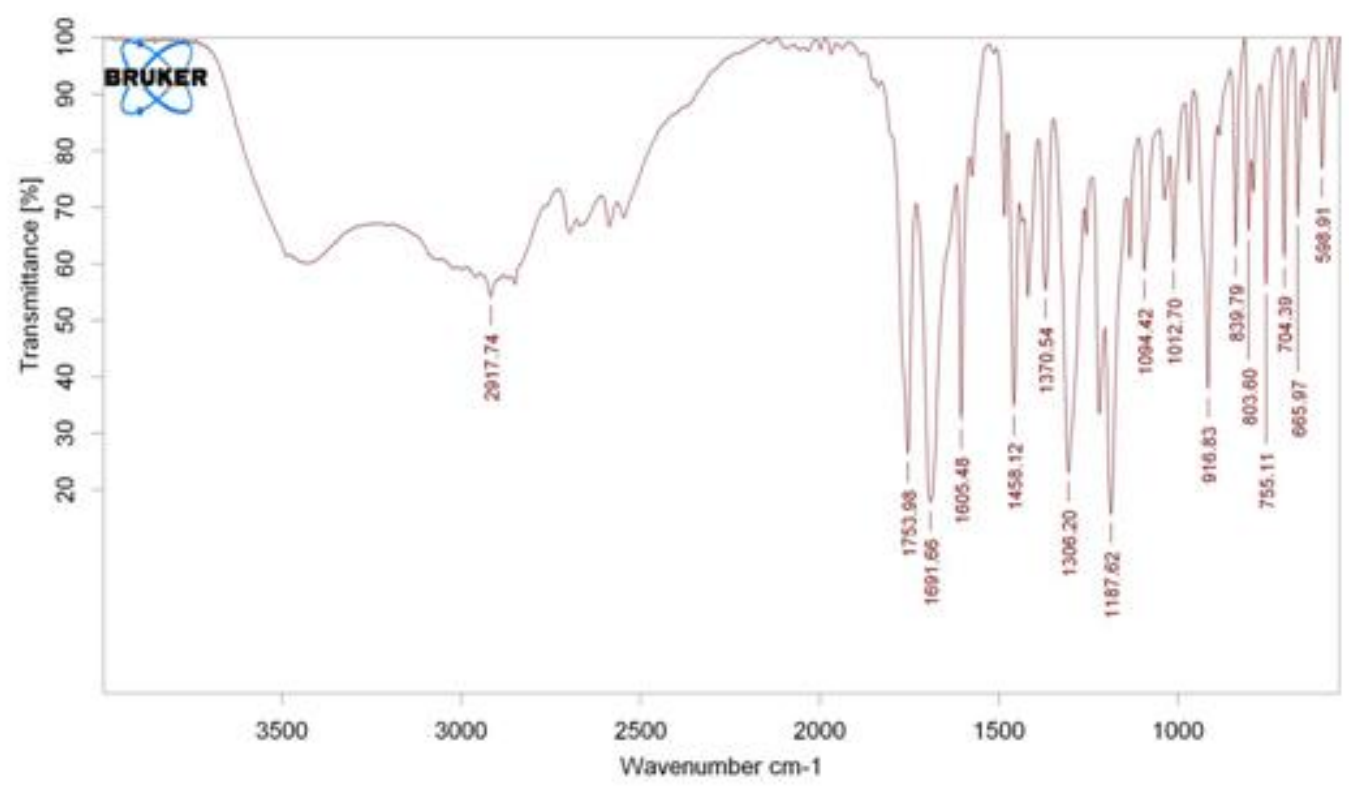

SAMPLE 5

Figure 3. FTIR of Drug + Na CMC 


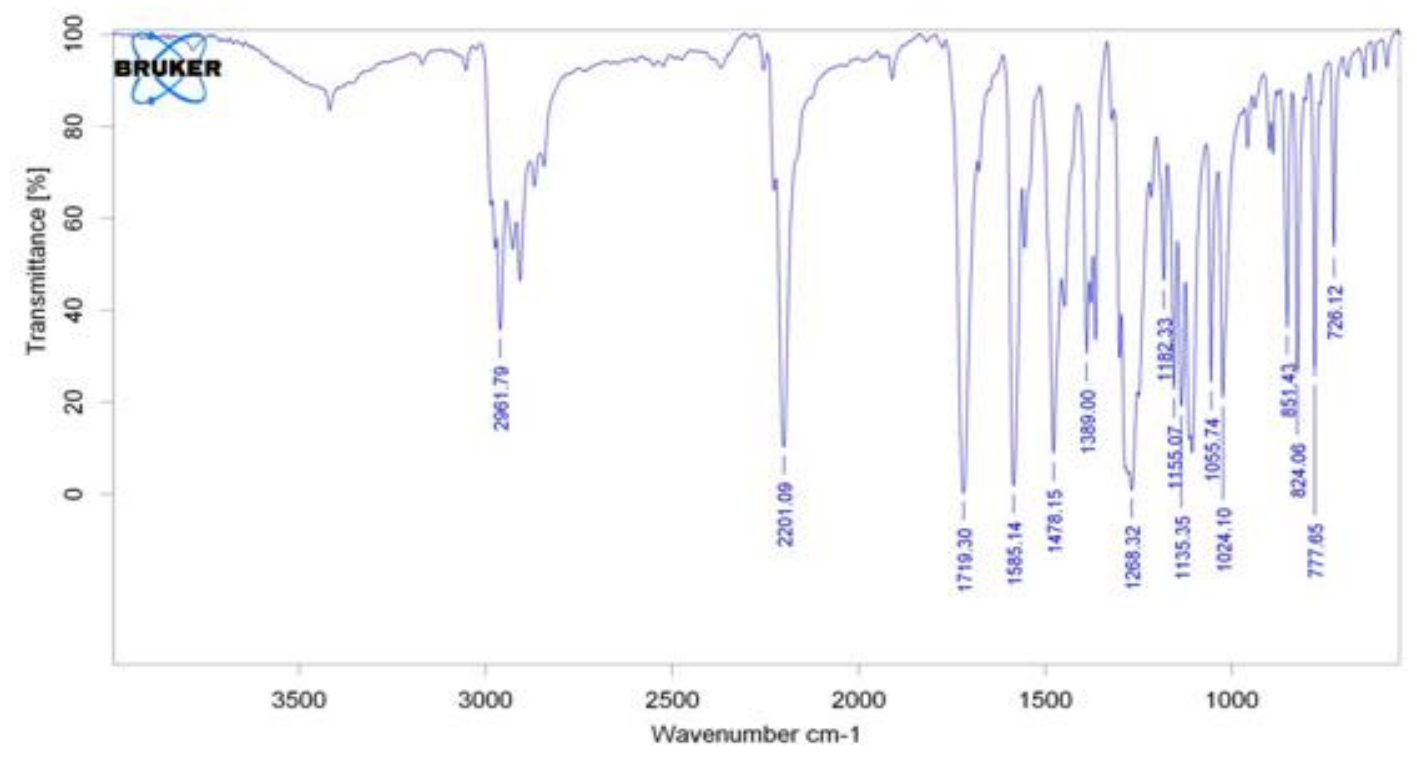

SAMPLE 2

Figure 4. FTIR of Drug + Xanthum gum

Standard Calibration curve of Ciclopirox:

Table 3. Calibration curve of Ciclopirox

\begin{tabular}{|c|c|}
\hline Concentration $(\mu \mathrm{g} / \mathrm{ml})$ & Absorbance $(\mathbf{n m})$ \\
\hline 0 & 0 \\
\hline 10 & 0.158 \\
\hline 20 & 0.266 \\
\hline 40 & 0.534 \\
\hline 60 & 0.768 \\
\hline 80 & 0.999 \\
\hline
\end{tabular}




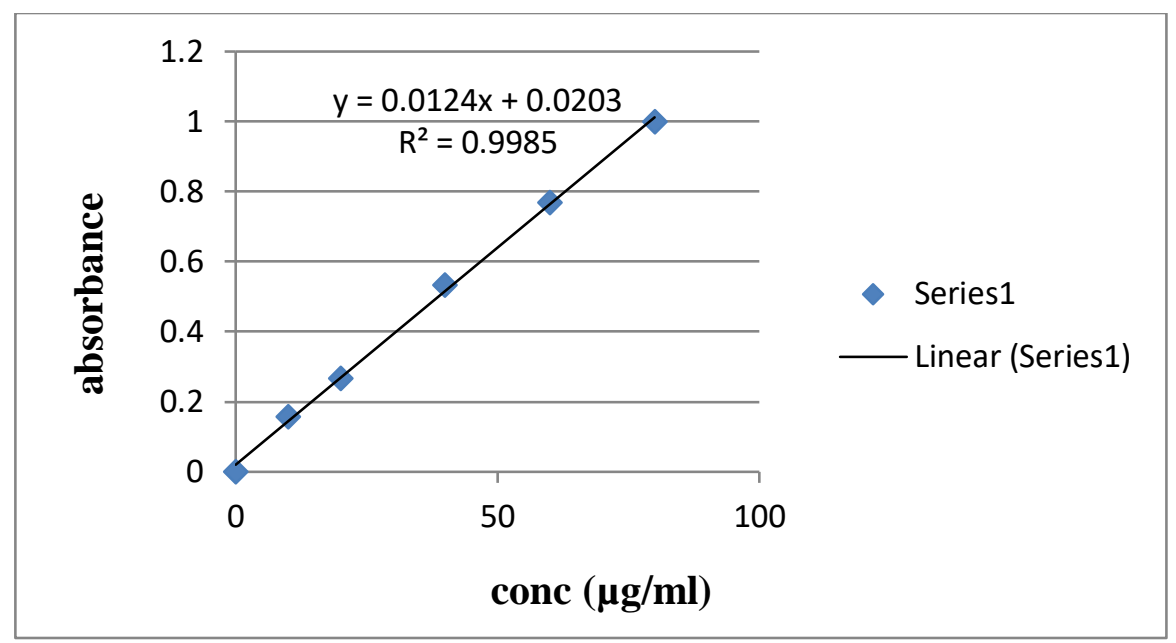

Figure 5. Standard graph of Ciclopirox

\section{Discussion:}

Ciclopirox beer's range concentration was found to be in the range using $\mathrm{pH} 7.4$ phosphate buffer solution. The regression value was closer to 1 indicating the method obeyed Beer-lambert's law as it was linear.

\section{Physical appearance:}

The formulated emulgels were examined for their colour, homogeneity, consistency and phase separation after $24 \mathrm{hr}$ of preparation. They were white, homogenous, transparent to white opaque and form viscous gel preparation with a smooth homogenous appearance and there was no significant phase separation in the formulations.

Table 4. Physical parameters of formulated batches

\begin{tabular}{|c|c|c|c|c|}
\hline Formulation & Homogeneity & Consistency & Phase separation & Gelling capacity \\
\hline F1 & Excellent & Excellent & None & + \\
\hline F2 & Excellent & Excellent & None & + \\
\hline F3 & Excellent & Excellent & None & + \\
\hline F4 & Excellent & Excellent & None & ++ \\
\hline F5 & Excellent & Excellent & None & ++ \\
\hline F6 & Excellent & Excellent & None & ++ \\
\hline
\end{tabular}

pH Measurement:

Measurement of $\mathrm{pH}$ is very important for topical preparations otherwise it leads to irritation to the skin. All the formulation has a $\mathrm{pH}$ around normal $\mathrm{pH}$ of skin and wouldn't produce any skin irritation.

Table 5. pH values of Emulgels

\begin{tabular}{|c|c|}
\hline Formulation code & $\mathbf{p H}$ \\
\hline F1 & 6.68 \\
\hline F2 & 6.44 \\
\hline F3 & 6.25 \\
\hline F4 & 6.48 \\
\hline
\end{tabular}




\begin{tabular}{|c|c|}
\hline F5 & 6.56 \\
\hline F6 & 6.37 \\
\hline
\end{tabular}

Discussion: The $\mathrm{pH}$ of formulation F1 -F6 was found to be in the range of 6.25-6.68.

Drug content:

Table 6. Drug content values of Ciclopirox Emulgel

\begin{tabular}{|c|c|}
\hline Formulation code & Drug content \\
\hline F1 & 96.5 \\
\hline F2 & 94.6 \\
\hline F3 & 98.5 \\
\hline F4 & 96.7 \\
\hline F5 & 97.0 \\
\hline F6 & 95.6 \\
\hline
\end{tabular}

Discussion: The drug content was found to be in the range of $94.6-98.5 \%$ for all the formulations indicating uniform distribution of drug.

\section{Spreadability}

Sreadability indicates ease of application. It tells about delivery of correct dose of drug. The spreadability of Sodium CMC based emulgel formulations \&Xanthan gum and Carbapol based formulation is depicted in table 13. By observing all formulations it was concluded that all the developed formulation showed acceptable spreadability. Carbopol based formulations showed better spreadability than Sodium CMC and Xanthan gum based.

Table 7. Spreadability of Emulgel formulations:

\begin{tabular}{|l|c|c|c|c|c|c|}
\hline Formulations & F1 & F2 & F3 & F4 & F5 & F6 \\
\hline Spreadability & 98 & 113 & 119 & 106 & 114 & 110 \\
& & & & & & \\
\hline
\end{tabular}

\section{In -vitro drug release study:}

The in- vitro release study of Ciclopirox from all formulations in $7.4 \mathrm{pH}$ buffer was conducted for a period of $12 \mathrm{hrs}$. 
Table 8. In-vitro drug release of Emulgel formulations

\begin{tabular}{|c|c|c|c|c|c|c|}
\hline Time & F1 & F2 & F3 & F4 & F5 & F6 \\
\hline 15 & 10.2 & 8.8 & 18.1 & 9.1 & 8.0 & 14.3 \\
\hline 30 & 21.2 & 14.4 & 29.2 & 18.2 & 18.6 & 23.6 \\
\hline 60 & 37.3 & 23.2 & 42.2 & 28.4 & 22.4 & 40.3 \\
\hline 90 & 52.2 & 30.8 & 58.1 & 49.8 & 38.9 & 59.0 \\
\hline 120 & 68.8 & 51.2 & 76.1 & 60.7 & 50.0 & 72.8 \\
\hline 150 & 73.4 & 60.07 & 89.1 & 70.3 & 59.1 & 85.0 \\
\hline 180 & 89.9 & 79.3 & 97.2 & 84.6 & 76.6 & 91.0 \\
\hline
\end{tabular}

The in-vitro drug release from all formulations F1-F6 can be observed and can be ranked in descending order $\mathrm{F} 3>\mathrm{F} 6>\mathrm{F} 1>\mathrm{F} 4>\mathrm{F} 2>\mathrm{F} 5$. Of all the formulations, F3 has shown good drug release of $97.2 \%$ at the end of 180 mins.

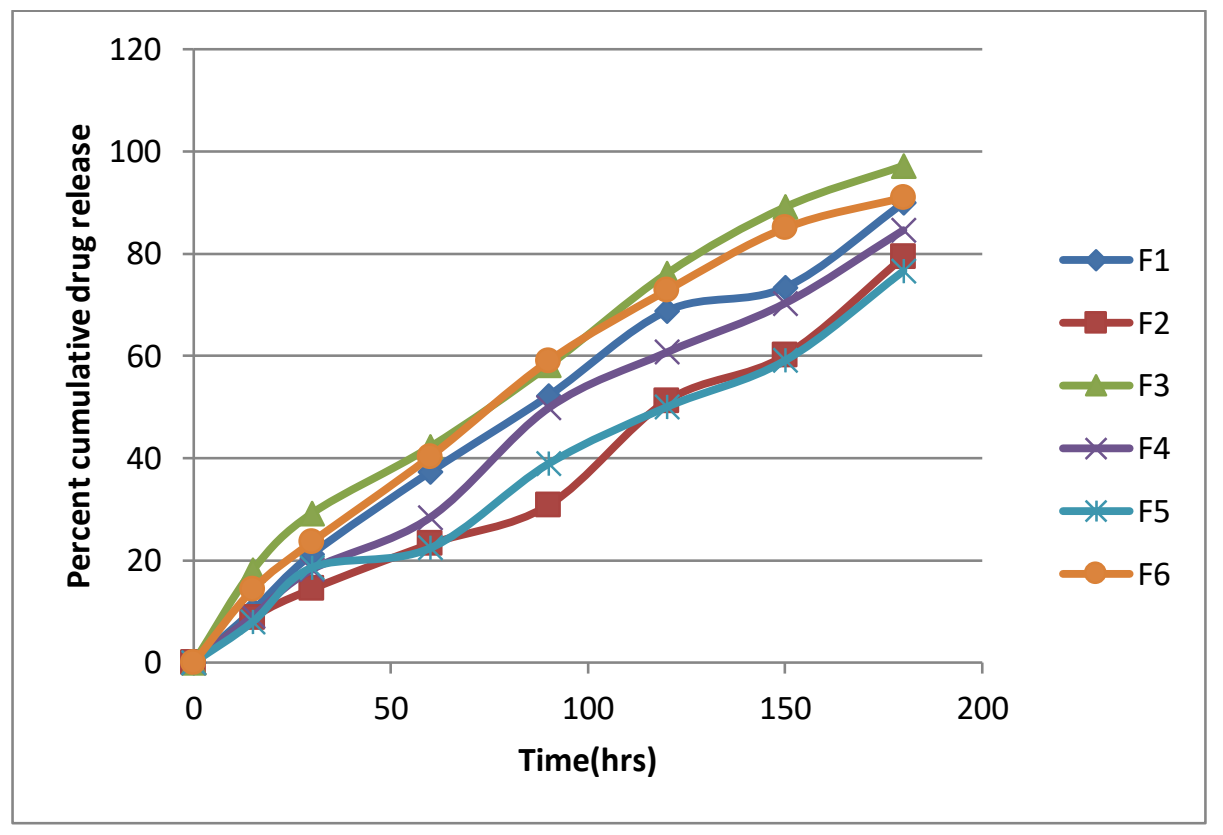

Figure 6. In-vitro drug release of F1-F6 Ciclopirox emulgel 


\section{Drug release kinetic studies:}

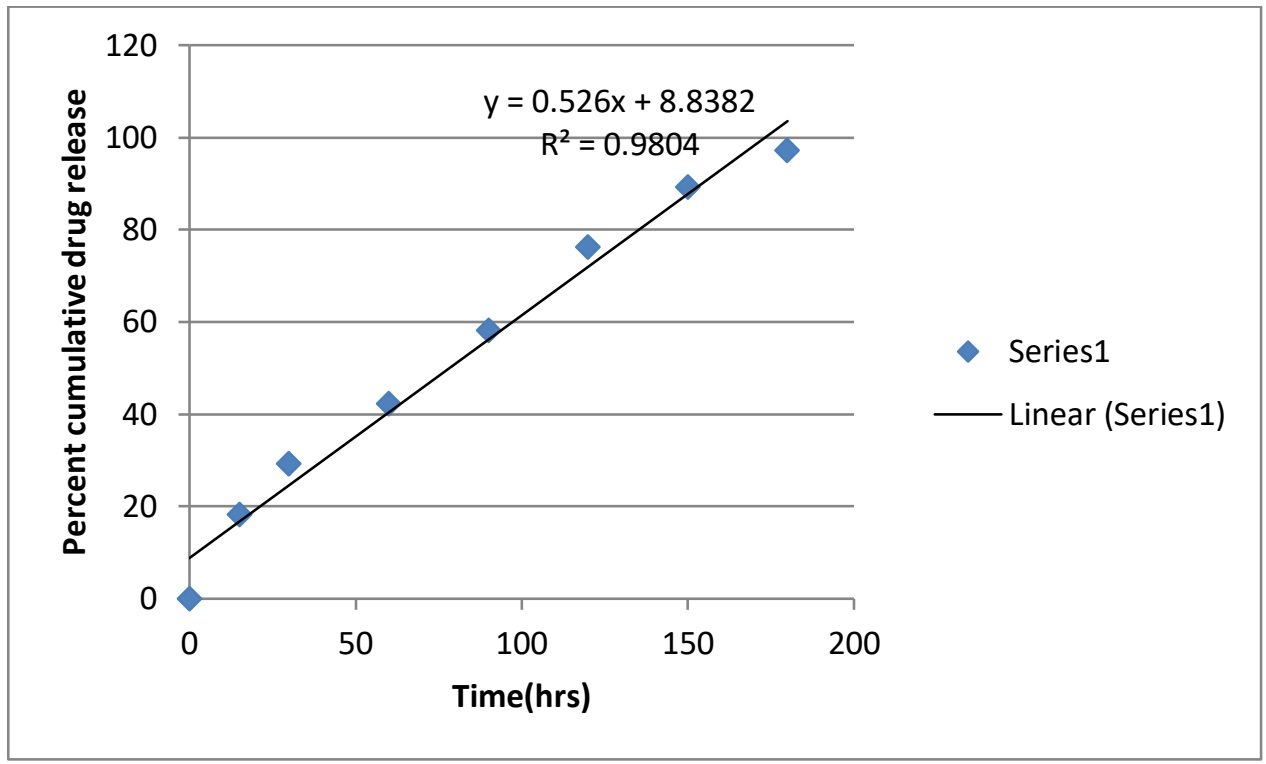

Figure 7. Zero order release kinetics

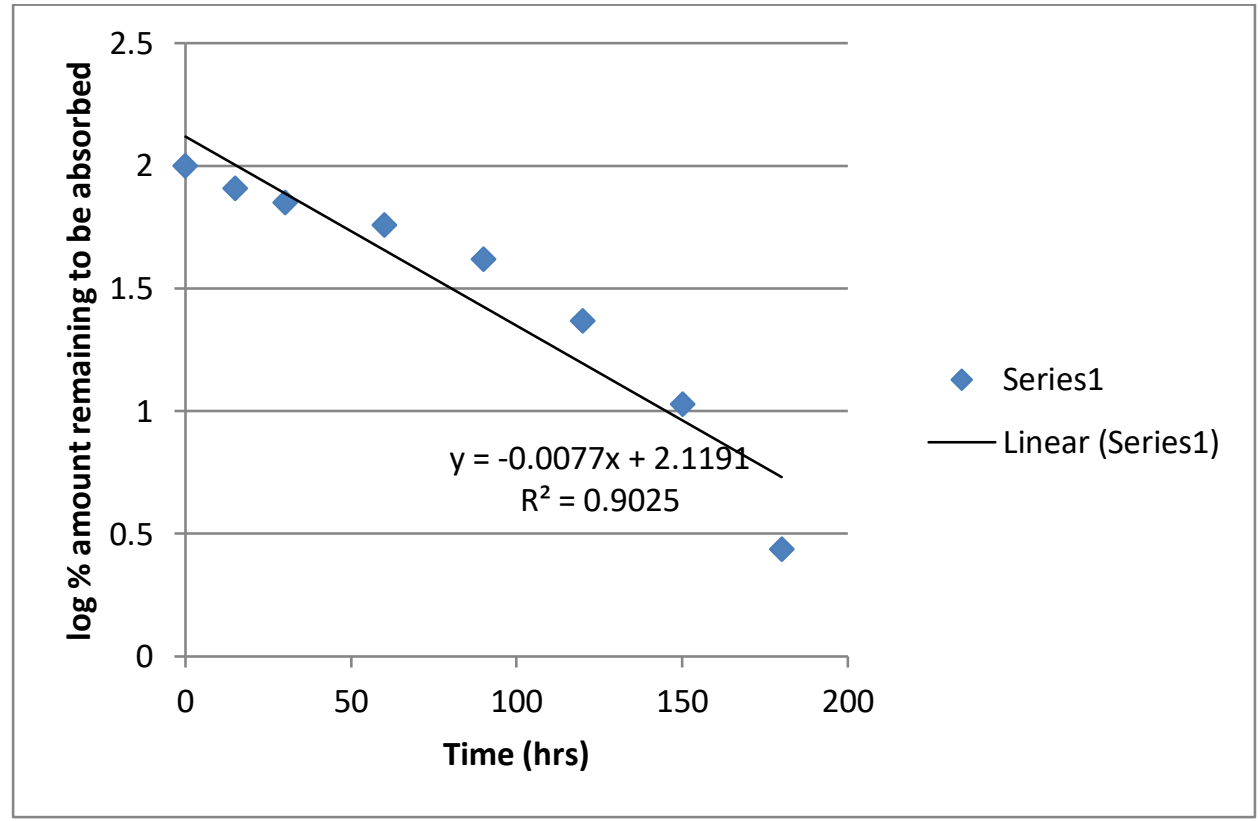

Figure 8. First order release kinetics 


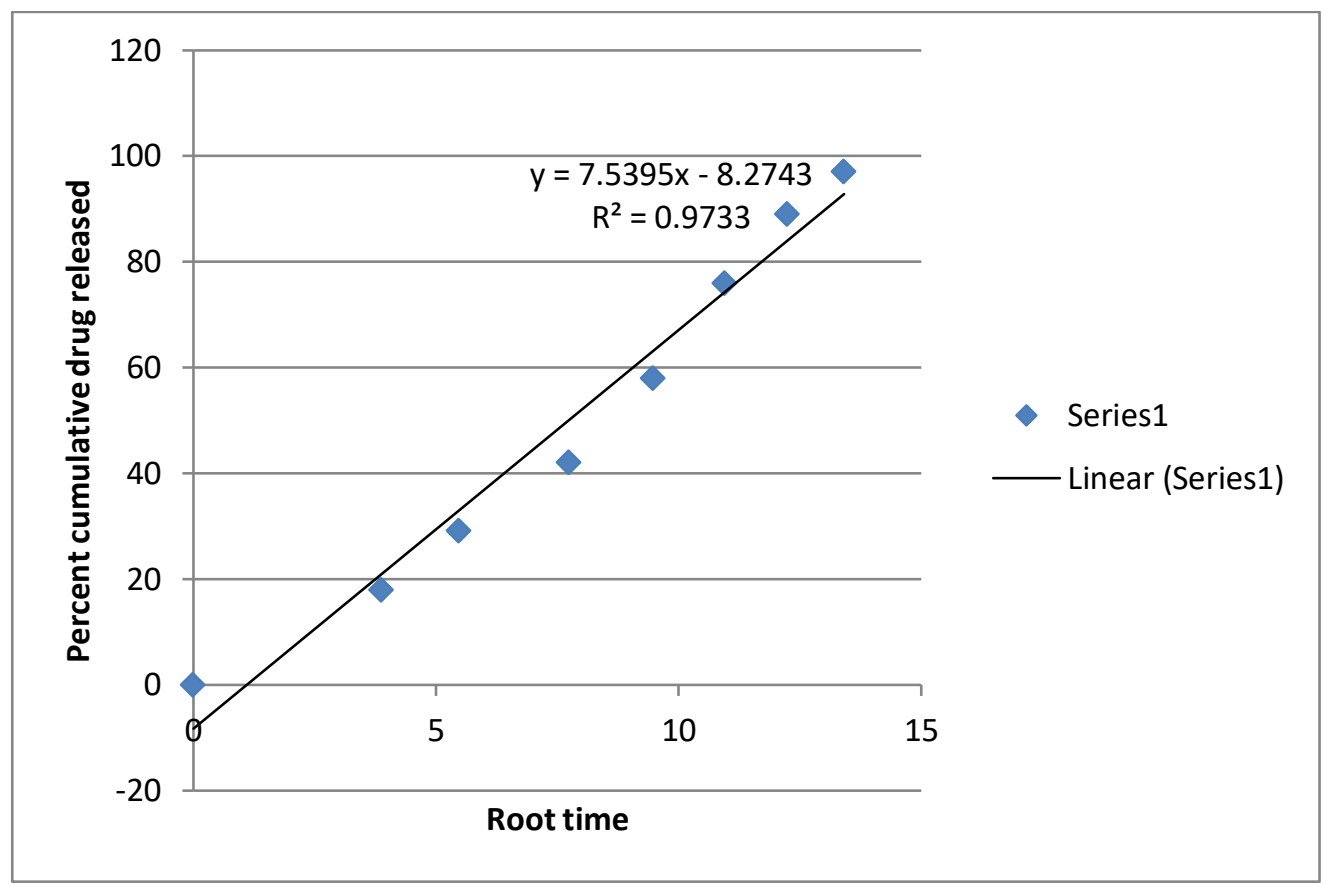

Figure 9. Higuchi release plot

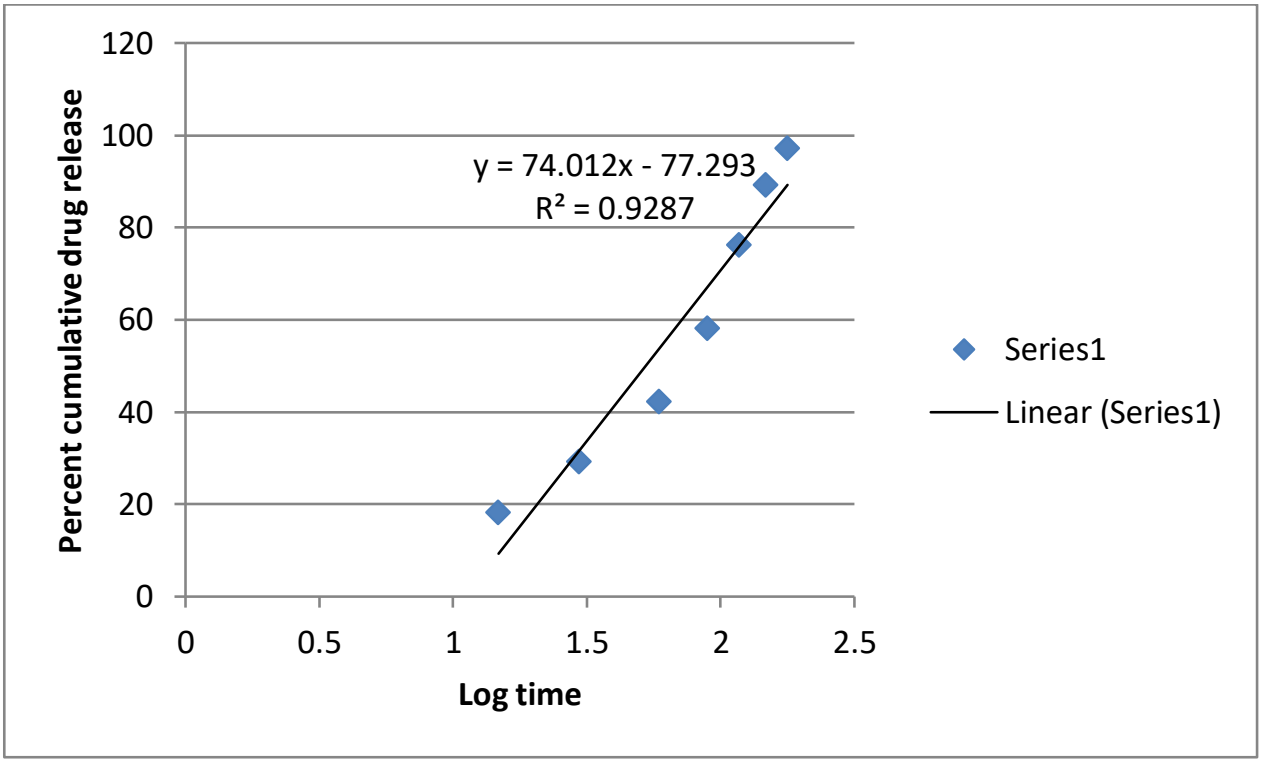

Figure 10. Korsemeyer- peppas plot 
The in-vitro dissolution data for best formulation F3 were fitted into different kinetic models .i.e, zero order, first order, Higuchi and Korsemeyer-peppas. Optimized formulation F3 shows $\mathrm{R}^{2}$ value as 0.9804. As its value is nearer to 1 it is said to follow zero order kinetics. The mechanism of drug release is further confirmed by Korsemeyer-peppas plot.

Table 9. R2 values

\begin{tabular}{|l|l|l|l|l|}
\hline Formulation & Zero order & First order & Higuchi & Korsemeyer peppas \\
\hline F3 & 0.9804 & 0.9025 & 0.9733 & 0.9287 \\
\hline
\end{tabular}

\section{Conclusion}

In the present study an attempt was made to prepare Ciclopirox Emulgel using different polymers in different concentrations. The Emulgels provided better therapeutic efficacy owing to continuous availability of drug over a prolonged period of time and it may be concluded from the result obtained from evaluation parameters that with increase in concentration of polymer ,the diffusion of drug through membrane decreases.

\section{Acknowledgment}

Authors are also thankful to management of Nalla Narasimha Reddy Group of Institutions, Chowdariguda, Ghatkesar and students for completing this work effectively.

\section{References}

1) Jankipatel, Juitrivedi and Dr. Sunita chudhary, "Formulation and Evaluation of Diacere in Emulgel for psoriatic Arthrities", International journal of Pharmaceutical research and bioscience. vol. 3, no. 2, (2014), pp. 625-638.

2) Anil R. Phad, Nandgude Tanaji Dilip and R. Sundara Ganapathy, "A Comprehensive Review for Topical Delivery of Hydrophobic Drugs", Asian Journal of Pharmaceutics. vol. 12, no. 2, (2018), pp.382-393.

3) Sushil kumar, Sushama Talegaonkar, Lalit M.Negi and Zeenat I.Khan, "Design and development of Ciclopirox topical nanoemulsion gel for the treatment of subungual onchomycosis",Indian Journal of Pharmaceutical Education and Research.vol.46, no. 4,( 2012),pp.305-311.

4) Snehal P. Mulye, Kiran A. Wadkar and Manish S. Kondawar, "Formulation, Development and Evaluation of Indomethacin Emulgel", Pelagia Research Library, Der Pharmacia Sinica. vol. 4, no. 5, (2013), pp 31-45.

5) Effionora anwar, Dellyr amadon and Harmita, "Formulation and Evaluation of gel and Emulgel of chili extract (capsicum Frutescensl.) as topical dosage forms", International journal of pharmacy and pharmaceutical sciences. vol. 6, no.3,(2014),pp.13-16.

6) V. Naga Sravan Kumar Varma*, P.V. Maheshwari, M. Navya, Sharath Chandra Reddy, H.G. Shivakumar and D.V. Gowda, "Calcipotriol delivery into the skin as Emulgel for effective permeation", King Saud University Saudi Pharmaceutical Journal. vol.22, no. 6, (2014), pp.591599.

7) K. Navaneetha, Asma Begum, P.Sumalatha, D.Vinitha, J. Sravan and Krishna Mohan Chinnala, "Formulation and In-Vitro Evaluation of Capsaicin Emulgel for Topical Delivery", Sch. Acad. J. Pharm. vol.6, no. 6, (2017), pp. 281-287.

8) Rachit Khullar, Deepinder Kumar, Nimrata Seth and Seema Saini, "Formulation and Evaluation of Mefenamic acid Emulgel for topical delivery", King Saud University Saudi Pharmaceutical Journal. vol. 20, (2012), pp. 63-67.

9) Rajesh Asija, Nitin Nama and Deepak Sharma, "Development and Evaluation of novel Fluticasone Propionate Emulgel for topical drug delivery", Journal of Chemical and Pharmaceutical Research. vol. 7, no. 2, (2015),pp.772-780. 